\title{
PEMEROLEHAN BAHASA INDONESIA PADA ANAK USIA 0-2 TAHUN: KAJIAN PSIKOLINGUISTIK
}

\author{
Hollysa Andini \\ Prodi Pendidikan Bahasa Indonesia \\ Pascasarjana, Universitas Mataram \\ Jl. Pemuda No. 35 Mataram 83125, Nusa Tenggara Barat \\ Email: icokk22jinyesever@gmail.com
}

\begin{abstract}
This research examines the process of acquiring bahasa Indonesia for the 0-2 years old children in term of phonology and morphology. The research was conducted in one housing resort in Rancak city, the district of Praya, central Lombok namely BTN Pujawan Permai. The reason is that because the people living in this housing resort come from variety of places. In collecting data the researcher applied theory of psycholinguistic using field notes and interview the subjects. The results are as follows: First, phonologically, the 0-2 years old children are still not able to pronounce some phones clearly such as the fricative consonant [r] which they are changed into lateral consonant [1]. Second, morphologically, children are able to use nouns, adjectives, verbs and some simple phrases correctly event their pronunciation is still not very clear.
\end{abstract}

Key words: Psycholinguistic, method of listen and talk (interviewing).

\section{DOI: 10.30957/lingua.v15i1.429.}

\section{PENDAHULUAN}

Mulai dari sebelum lahir atau sejak masih di dalam kandungan, manusia sudah dibekali dengan kemampuan bawaan (innate capacity) oleh sang Pencipta Yang Maha Kuasa dengan alat atau Perangkat Pemerolehan Bahasa yang oleh (D.H Brown, 1987 dalam E.Aminudin Aziz,1995 dan Neil dalam Tarigan, 1998) dinamakan Language Acquisition Device (LAD) untuk berinteraksi (berkomunikasi). Tidak hanya menggunakan bahasa dalam bentuk kata-kata (verbal) melainkan menggunakan bahasa nonverbal. Di dalam kandungan ia menendang dan bergerak-gerak, menandakan bahwa si anak yang masih janin itu ingin berinteraksi dengan ibunya. Tentu saja banyak faktor yang dapat mendukung serta mempengaruhi perkembangan kemampuan anak dalam pemerolehan bahasa.

Di saat si anak dilahirkan, komunikasi pertama yang ia lontarkan adalah suara tangisan. Tangisan adalah pertanda bahwa anak (bayi) tersebut terlahir dengan sebuah embrio kehidupan yang sekaligus juga merupakan embrio bahasa yang siap dikembangkan oleh orang tuanya (ibu dan ayahnya) serta lingkungannya kelak agar dapat berkomunikasi dengan sesamanya baik secara verbal maupun nonverbal. 
Perkembangan bahasa seorang anak amat tergantung pada bahasa sehari-hari yang dipakai berinteraksi (berkomunikasi) oleh orang tua dan masyarakat sekitarnya selaku lingkungan keseharian si anak tersebut. Bila dalam keluarga sehari-hari orang tuanya berbicara dengan bahasa ibu (mother tongue) bahasa Sasak misalnya maka bahasa yang berkembang pada anak tersebut adalah bahasa ibu (bahasa Sasak) dan itulah bahasa pertama yang ia peroleh dalam proses pemerolehan bahasa ((language acquisition) dalam kehidupannya.

Perkembangan bahasa pada seorang anak usia 0-2 tahun tentu saja masih sangat terbatas. Ia masih sebatas meniru kata-kata yang ia dengar dari sang ibu/ayahnya yang secara informal (kekeluargaan) terus menerus mereka ucapkan setiap saat, tidak perduli apa sang anak paham atau tidak atas apa yang mereka perdengarkan kepada sang anak.

Psikolinguistik menjelaskan dengan sangat rinci tahapan-tahapan perkembangan seorang anak dalam memperoleh bahasa untuk melakukan komunikasi sesuai dengan usianya. Psikolinguistik merupakan ilmu hibrida, yakni, ilmu yang merupakan gabungan antara dua ilmu: psikologi dan linguistik. Benih ilmu ini sebenarnya sudah tampak pada permulaan abad ke 20 ketika psikolog Jerman, Wilhelm Wundt menyatakan bahwa bahasa dapat dijelaskan dengan dasar prinsi-prinsip psikologis. Sementara, di benua Amerika kaitan bahasa dengan ilmu jiwa juga mulai tumbuh. Perkembangan ini dibagi menjadi empat tahap: (a) tahap formatif, (b) tahap linguistik, (c) tahap kognitif, dan (d) tahap teori psikolinguistik, realita psikologis, dan ilmu kognitif (Kess, 1992).

Dardjowidjojo (2005) secara rinci menyebutkan bahwa psikolinguistik mempelajari empat topik utama: (a) komprehensi, yakni proses-proses mental yang dilalui oleh manusia sehingga mereka dapat menangkap apa yang dikatakan orang dan memahami apa yang dimaksud, (b) produksi, yakni, proses-proses mental pada diri kita yang membuat kita dapat berujar seperti yang kita ujarkan, (c) landasan biologis serta neurologis yang membuat manusia bisa berbahasa, dan (d) pemerolehan bahasa, yakni, bagaimana anak memperoleh bahasa mereka. Istilah pemerolehan dipakai untuk padanan istilah bahasa Inggris acquisition, yakni, proses penguasaan bahasa yang dilakukan oleh anak secara natural pada waktu dia belajar bahasa ibunya (native language). Artinya, pemerolehan ini merupakan cara manusia menyerap informasi yang kemudian bisa dipahami sehingga komunikasi antar penutur itu dapat berlangsung dengan baik.

Itu sebabnya di sini penulis merasa sangat tertarik untuk meneliti bunyi-bunyi pendek atau fonetik bahasa anak usia 0-2 tahun tersebut dalam berinteraksi (berkomunikasi) dengan orang tuanya. Bunyi-bunyi pendek tersebut dilatih berulangulang secara terus menerus dan bertubi-tubi yang kelak dalam tahapan perkembangan bahasa anak, akan tumbuh berkembang menjadi kata-kata dan pada tahapan tertentu kelak akan menjadi kalimat-kalimat lengkap yang dapat dipahami oleh semua orang.

\section{METODE}

Umumnya penghuni komplek perumahan itu barasal dari berbagai daerah yang sehari-harinya menggunakan bahasa daerah asalnya, sehingga sulit untuk saling 
memahami di saat berinteraksi (berkomunikasi) dengan sesama bila menggunakan bahasa daerah masing-masing.

Pada bagian ini peneliti tidak hanya menjabarkan tentang metode penelitian tetapi juga membahas tentang metode pemerolehan, pengalisisan dan penyajian data. Penelitian ini menggunakan metode kualitatif sebagaimana yang dijelaskan oleh Bogdan dan Taylor (1975:5) dalam Moleong (2004) yang mendeskripsikan metodologi kualitatif sebagai prosedur penelitian yang menghasilkan data deskriptif berupa katakata tertulis atau lisan dari orang-orang dan perilaku yang dapat diamati. Data-data yang didapatkan dari penelitian ini berupa kata-kata lisan yang kemudian akan ditranskripkan ke dalam tulisan.

Dalam pemerolehan data berkaitan dengan penelitian ini yang dikhususkan pada pemerolehan bahasa berupa pemerolehan fonologi dan morfologi pada anak umur 0-2 tahun menggunakan beberapa metode. Metode yang digunakan adalah metode simak, dan metode cakap. Penggunaan metode-metode ini diharapkan akan dapat memaksimalkan data yang diperoleh.

Metode simak merupakan salah satu metode yang sangat membantu dalam penyediaan data karena metode ini lebih bersifat natural (alamiah), metode ini sejajar dengan metode observasi (pengamatan). Mahsun (2017) metode ini memliki teknik dasar yaitu teknik simak bebas libat cakap (SBLC) dan simak libat cakap (SLC).

Kedua teknik inipun digunakan oleh peneliti, dimana teknik simak bebas libat cakap, peneliti hanya akan berperan sebagai pengamat secara penuh, artinya peneliti akan melihat semua perilaku baik itu bahasa ataupun gerak-gerik subyek penelitian tanpa ikutserta berkomunikasi secara verbal dan sosial kemudian pengamat mencatat data-data yang diperoleh. Penggunaan alat-alat bantu dalam pengamatanpun sangat diperlukan baik berupa rekaman audio (suara) dan alat rekam video (suara dan gambar). Selain itu, juga akan didukung oleh teknik simak libat cakap yang memungkinkan peneliti tidak hanya sebagai pengamat tetapi akan ikut berkomunikasi dan berperanserta dengan subyek penelitian guna mendapatkan data yang lebih banyak dan lebih akurat.

Analisis data kualitatif menurut Bogdan \& Biklen (1982) dalam Moleong (2004) adalah upaya yang dilakukan denga jalan bekerja dengan data, mengorganisasikan data, memilah-milahnya menjadi satuan yang dapat dikelola, mensistesiskannya, mencari dan menemukan pola, menemukan apa yang pentig dan apa yang dipelajari dan memutuskan apa yang dapat diceritakan kepada orang lain. Dalam penganalisisan data, peneliti terlebih dahulu mengelompokkan data yang termasuk ke dalam pemerolehan fonologi dan pemerolehan mofologi anak usia 0-2 tahun.

\section{HASIL DAN BAHASAN}

Kajian ini membahas masalah pemerolehan fonologi dan morfologi pada anak usia 0-2 tahun yang orang tuanya menggunakan bahasa Indonesia dalam berinteraksi (berkomunikasi) sehari-hari dalam keluarganya, sementara masyarakat sekelilingnya berinteraksi (berkomunikasi) dengan menggunakan bahasa daerah (bahasa Sasak). 


\section{Pemerolehan fonologi pada anak usia 0-2 tahun.}

\section{a. Pemerolehan Fonologi Anak Usia 0 - 0,5 tahun}

Pemerolehan fonologi pada anak usia ini tidak dapat dideskripsikan, karena setelah penelitian tidak didapatkan ucapan atau ujaran. Bukan ujaran yang keluar melainkan hanya sebuah ekspresi berupa senyum, tawa ataupun menangis. Dapat disimpulkan bahwa pada usia ini anak melalui tahapan babbling atau celotehan yang sulit dipahami namun, celotehan itulah yang digunakan anak untuk berkomunikasi.

\section{b. Pemerolehan Fonologi Anak Usia 0,6 - 1 tahun}

Pemerolehan fonolgi pada usia ini, anak sudah mampu mengeluarkan beberapa bunyi berupa bunyi vocal dan bunyi konsonan. Berdasarkan transkrip data, pemerolehan pada tatanan fonolgi untuk usia ini belum dapat dideskripsikan, seperti pada bunyi [pa], [ta], [ba]. [ma]. Walaupun demikian, pemerolehan bahasa dapat dipahami berdasarkan unsure bunyi yang dikeluarkan. Bunyi vokal [a] adalah yang terdengar jelas, dan bunyi konsonan BL [b] dan [p], konsonan AA [t], dan konsonan nasal BL [m].

\section{c. Pemerolehan Fonologi Anak Usia 1 - 1,5 tahun}

Data transkrip penelitian menunjukkan bahwa pada ausia ini anak sudah mulai mengucapkan kata-kata yang jelas. Produksi bunyi yamg muncul berupa kata-kata sebagai berikut.

\begin{tabular}{|l|l|l|}
\hline /unda/ & [bunda] & "ibu" \\
\hline /anyah/ & {$[$ ayah] } & "ayah" \\
\hline /nyinyik/ & {$[$ [ninik] } & "nenek" \\
\hline /minyum/ & {$[$ [minUm] } & "minum" \\
\hline /puyang/ & [puyAi்] & "pulang" \\
\hline /uyet/ & [ulat] & "ulat" \\
\hline /tidun/ & [tidUr] & "tidur" \\
\hline /cepedah/ & [sepEda] & "sepeda" \\
\hline /dapun/ & [dapur] & "dapur" \\
\hline /Kaman/ & [kamar] & "kamar" \\
\hline
\end{tabular}

Berdasarkan bunyi-bunyi yang diucapkan di atas, anak memperoleh bahasa pada tatanan fonologis dari segi artikulatoris muncul berupa VKVK atau KVK menunjukkan bahwa bunyi bahasa tersebut mengandung nilai fonemik yang dapat dimengerti oleh pendengar. Bunyi vokal [a], [i], [e], dan [u] mendominasi diucapkan oleh anak. Sedangkan, bunyi konsonan yang muncul sesuai data tersebut, seperti : [n], [d], [h], [k], [m], [p], [y], [t], [l], [c], dan[ฑं]. Bunyi nasal AA [n] merupakan nasal yang muncul di tengah dan nasal BL [m] muncul di awal. Bunyi konsonan DV [k], BL [p], AA [t], dan [d] muncul di awal. 


\section{d. Pemerolehan Fonologi Anak Usia 1,6 - 2 tahun}

Pemerolehan fonologis anak usia 1,6 tahun sesuai dengan transkrip data hasil penelitian sudah mulai mampu mengucapkan kata-kata yang jelas.

Bunyi vokal [a], [i], [u] yang muncul ketika anak usia 2 tahun berbicara bisa dikategorikan sudah sesuai dengan keuniversalan dalam pemerolehan bahasa, selain itu juga muncul vokal [ ], [ ] dan [o]. berikut data-datanya.

\begin{tabular}{|c|c|c|}
\hline \multicolumn{2}{|c|}{ Bunyi vokal [a] muncul pada kata } & \multirow[b]{2}{*}{ "anggur” } \\
\hline /agu/ & [aígur] & \\
\hline /ambut/ & [rambut] & "rambut" \\
\hline /ayam/ & [ayam] & "ayam" \\
\hline \multicolumn{2}{|c|}{ Bunyi vokal, [ ], [ ] muncul pada kata } & \\
\hline /eyut/ & [p rut] & "perut" \\
\hline /ebek/ & {$\left[\begin{array}{lll}b & b & ?\end{array}\right]$} & "bebek" \\
\hline \multicolumn{2}{|c|}{ Bunyi vokal [i] muncul pada kata } & \\
\hline /igi/ & [gigi] & "gigi" \\
\hline \multicolumn{2}{|c|}{ Bunyi vokal [o] muncul pada kata } & \\
\hline /cetobeyi/ & [strob ri] & "strawberi" \\
\hline \multicolumn{2}{|c|}{ Bunyi vokal $[\mathrm{u}]$ muncul pada kata } & \\
\hline /uning/ & [kuni门] & "kuning" \\
\hline
\end{tabular}

Bunyi-bunyi konsonan yang muncul pada anak usia 2 tahun berdasarkan fakta yaitu berupa bunyi-bunyi ; [b], [d], [g], [h], [j], [k], [m], [n], [p], [t], [y] dan [iं]. Bunyi konsonan bersuara BL [d] dan konsonan tidak bersuara BL [p] muncul dalam bentuk seperti:

\begin{tabular}{|l|l|l|}
\hline /dung/ & [hiduiं] & "hidung" \\
\hline /apel/ & [ap 1] & "apel" \\
\hline
\end{tabular}

Pada ujaran anak usia 2 tahun di atas terjadi penghilangan bunyi konsonan frikatif GL [h] dan vokal [i] serta penghilangan bunyi vokal [a]. Konsonan lain seperti bunyi afrikatif FP [c], bunyi DV [g], bunyi nasal $[\dot{\eta}]$, bunyi frikatif $\mathrm{GL}[\mathrm{h}]$ dijumpai pada kata-kata berikut: 


\begin{tabular}{|l|l|l|}
\hline /picang/ & [pisaiं] & "pisang" \\
\hline /anggun/ & [aijgur] & "anggur" \\
\hline /angga/ & [mai்ga] & "mangga" \\
\hline /igi/ & [gigi] & "gigi" \\
\hline /cikush/ & [tikUs] & "tikus" \\
\hline /jajah/ & [gajah] & "gajah" \\
\hline
\end{tabular}

\section{Pemerolehan morfologi pada anak usia 2 tahun}

Pemerolehan bahasa anak usia 0-2 tahun pada tataran morfologi dilakukan analisis tentang bentuk kata berikut ini:

\section{a. Pemerolehan morfologi anak usia 0-1 tahun}

Pemerolehan morfologi untuk anak usia 0-2 tahun setelah dilakukan transkripsi atas data hasil penelitian didapatkan fakta bahwa untuk anak usia 0-1 tahun tidak dapat diuraikan disini karena bunyi bahasa yang diucapkannya masih belum dapat diidentifikasikan.

\section{b. Pemerolehan morfologi anak usia 1,5 tahun}

Merujuk pada bunyi bahasa yang diucapkan oleh anak usia 1,5 tahun pada transkripsi data, dapat dikatakan bahwa anak dalam usia tersebut mulai mampu memproduksi kata-kata yang tergolong monomorfemik, seperti berikut ini :

\begin{tabular}{|c|c|c|}
\hline /ibu/ & [ibu] & "ibu" \\
\hline /bapak/ & [bapa?] & "bapak" \\
\hline /loti/ & [loti] & "roti" \\
\hline /pegi/ & {$\left[\begin{array}{ll}p & g i\end{array}\right]$} & "pergi" \\
\hline /idun/ & [idun] & "tidur" \\
\hline /num/ & [num] & "minum" \\
\hline /puyang/ & [puyaí] & "pulang" \\
\hline /uduk/ & [udu?] & "duduk" \\
\hline /peda/ & {$[\mathrm{p} \mathrm{da}]$} & "sepeda" \\
\hline /bambah/ & [bambah] & "tambah" \\
\hline /ndah/ & [ ndah] & “sudah" \\
\hline
\end{tabular}

Selain bentuk monomorfemik, ditemukan juga pengucapan-pengucapan yang lebih dari satu kata walaupun secara fonologis mengalami perubahan bunyi, seperti berikut ini: 
Http://lingua.pusatbahasa.or.id; Email: presslingua@gmail.com

Center of Language and Culture Studies, Surakarta, Indonesia

Andini, Hollysa. 2018. Pemerolehan Bahasa Indonesia pada Anak Usia 0 2 Tahun:

Kajian Psikolinguistik. Lingua (2018), 15(1): 45 52. DOI: 10.30957/lingua.v15i.429.

\begin{tabular}{|l|l|l|}
\hline /acit tati/ & [acit tati] & "sakit kaki" \\
\hline /macan aciq/ & [macan aci?] & "makan nasi" \\
\hline /es coyim/ & [es coyim] & "es krim" \\
\hline /pegi cetoyah/ & [p gi cetoyah] & "pergi sekolah" \\
\hline /mau idun/ & [ mau idun] & "mau tidur" \\
\hline /daq num/ & [dak num] & "ndak minum" \\
\hline /puyang unda/ & [puyai unda] & "pulang bunda" \\
\hline /peda kakak/ & [p da kaka?] & "sepeda kakak" \\
\hline /bambah yagi/ & [bambah yagi] & "tambah lagi" \\
\hline /ndah nandi/ & [ ndah nandi] & "sudah mandi" \\
\hline
\end{tabular}

Berdasarkan fakta di atas dapat dikatakan bahwa anak usia 1,5 tahun sudah mampu memproduksi lebih dari satu kata yang tergolong kata majemuk.

\section{c. Pemerolehan morfologi anak usia 2 tahun}

Pemerolehan bahasa pada tataran morfologi bagi anak usia 2 tahun tidak terdapat perbedaan yang signifikan dengan anak usia 1,5 tahun. Fakta menunjukkan bahwa ujaran yang dikeluarkan masih berkisar satu atau dua kata dan kata benda adalah kata yang mendominasi perkembangan perolehan bahasanya setelah itu adalah kata kerja dan kata sifat yang juga mengalami perkembangan kosa katanya. Kata-kata berikut ini adalah untuk memperjelas hal tersebut di atas:

\begin{tabular}{|l|l|l|l|}
\hline Kata & Seharusnya & Arti kata & Jenis kata \\
\hline /ebek/ & {$[$ b b k] } & Bebek & Kata benda \\
\hline /ayam/ & [ayam] & Ayam & Kata benda \\
\hline /uyung/ & {$[$ buyung] } & Burung & Kata benda \\
\hline /maem/ & {$[$ makan] } & Makan & Kata kerja \\
\hline /nandi/ & [mandi] & Mandi & Kata kerja \\
\hline /dendong/ & [gendong] & Gendong & Kata kerja \\
\hline /toton/ & [kotor] & Kotor & Kata sifat \\
\hline /uning/ & [kuning] & Kuning & Kata sifat \\
\hline Dan lain-lain & \multicolumn{3}{|l}{} \\
\hline
\end{tabular}

Jenis kata majemuk yang diucapkan anak usia 2 tahun ini tidak banyak, hanya berkisar pada kata-kata yang tergolong mudah diucap dan pendek-pendek sebatas kemampuan yang sesuai dengan usianya .

\section{SIMPULAN}

Penelitian ini menyimpulkan bahwa perkembangan embrio bahasa anak bisa berbeda-beda pada setiap individunya, bisa berkembang cepat dan bisa juga lamban, tergantung pada tingkat atau jenjang usianya, kemampuan orang tuanya dan lingkungan yang aktif untuk mengembangkannya. Semakin tinggi usia seorang anak, semakin tinggi pula perkembangan kemampuan berbahasanya. Pemerolehan bahasa untuk 
tataran morfologi pada anak usia 19 bulan, berdasarkan jenis kata maka dapat dikatakan bahwa anak dalam usia tersebut telah mampu juga memproduksi kata benda dan kata kerja bahkan kata sifat tapi masih dalam bentuk kata-kata tunggal dan masih sering salah ucap. Sampai genap berusia 24 bulan (2 tahun) seorang anak sudah mampu memproduksi kata-kata (ujaran-ujaran) yang lebih banyak dan tidak hanya sebatas satu atau dua kata saja melainkan lebih dari itu dimana untuk semetara waktu kata benda adalah kata yang mendominasi perkembangan perolehan bahasanya, setelah itu adalah kata kerja dan kata sifat yang juga mengalami perkembangan kosa katanya.

\section{DAFTAR PUSTAKA}

Aziz, Aminudin. 1995. Materi Pokok. Introduction to Linguistics. Modul 1 -6. Jakarta. Depdikbud. Ditjen Pendidikan Dasar dan Menengah. Proyek Peningkatan Mutu Guru SLTP Setara D-III.

Chaer, Abdul. 2009. Psikolinguistik, Kajian Teoritik. Jakarta. Rineka Cipta

Isnaini, Muhammad. 2014. Pemerolehan Bahasa Anak Usia 0-4 Tahun di Desa Terara Dan Relevansinya Pada Pembelajaran Bahasa Indonesia. Sebuah Kajian Psikolinguistik. Mataram. Program Pascasarjana Universitas Mataram

Mahsun. 2017. Metode Penelitian Bahasa, Tahapan, Strategi, Metode dan Tekniknya. Depok. Raja Grafindo Persada

Moleong, Lexy J. 2004. Metodologi Penelitian Kualitatif. Bandung. Remaja Rosdakarya

Tarigan, Henry Guntur, 1988. Pengajaran Pemerolehan Bahasa. Jakarta. Depdikbud. Ditjen Pendidikan Tinggi. Proyek Pengembangan Lembaga Pendidikan Tenaga Kependidikan. 